Please do not remove this page

RMIT

UNIVERSITY

\title{
Do perceptions of supervisors' safety responses mediate the relationship between perceptions of the organizational safety climate and Incident rates in the construction supply chain?
}

Lingard, Helen; Cooke, Tracy; Blismas, Nick

https://researchrepository.rmit.edu.au/esploro/outputs/9921858570801341/filesAndLinks?institution=61RMIT_INST\&index=null

Lingard, H., Cooke, T., \& Blismas, N. (2012). Do perceptions of supervisors' safety responses mediate the relationship between perceptions of the organizational safety climate and Incident rates in the construction supply chain? Journal of Construction Engineering and Management, 138(2), 234-241. https://doi.org/10.1061/(ASCE)CO.1943-7862.0000372

Document Version: Accepted Manuscript

Published Version: https://doi.org/10.1061/(ASCE)CO.1943-7862.0000372

Repository homepage: https://researchrepository.rmit.edu.au

(C) 2012 American Society of Civil Engineers

Downloaded On 2023/04/26 19:34:47 +1000 
Thank you for downloading this document from the RMIT Research Repository.

The RMIT Research Repository is an open access database showcasing the research outputs of RMIT University researchers.

RMIT Research Repository: http://researchbank.rmit.edu.au/

\section{Citation:}

Lingard, H, Cooke, T and Blismas, N 2012, 'Do perceptions of supervisors' safety responses mediate the relationship between perceptions of the organizational safety climate and incident rates in the construction supply chain?', Journal of Construction Engineering and Management, vol. 138, no. 2, pp. 234-241.

See this record in the RMIT Research Repository at:

http://researchbank.rmit.edu.au/view/rmit:16889

Version: Accepted Manuscript

Copyright Statement: (c) 2012 American Society of Civil Engineers

Link to Published Version:

http://dx.doi.org/10.1061/(ASCE)C0.1943-7862.0000372 


\title{
Do perceptions of supervisors' safety responses mediate the relationship between perceptions of the organizational safety climate and incident rates in the construction supply chain?
}

\author{
Helen Lingard ${ }^{1}$, Tracy Cooke $^{2}$ and Nick Blismas ${ }^{3}$
}

\begin{abstract}
A multi-level safety climate survey was conducted in three Australian organizations in the construction supply chain. A principal components analysis (with varimax rotation) yielded six distinct safety climate factors reflecting aspects of the organizational safety response (OSR), supervisors' safety response (SSR) and coworkers' safety response (CSR). Perceptions of top management commitment to safety (an aspect of OSR) and supervisors’ safety expectations (an aspect of SSR) were both significantly and inversely correlated with the combined medical treatment and lost time injury rate of workgroups in the analysis. Further, regression analysis revealed that perceptions of supervisors' safety expectations fully mediated the relationship between perceptions of top management commitment to safety and the workgroup injury frequency rate. The results highlight the critical role played by first-level supervisors in acting as the conduit, through which organizational safety priorities are communicated to the workforce.
\end{abstract}

\section{Keywords}

Safety climate, supervisors' safety response, lost time incidents, medical treatment incidents.

\footnotetext{
${ }^{1}$ Professor, School of Property, Construction and Project Management, RMIT University, GPO Box 2476, Melbourne, Victoria 3001, Australia

${ }^{2}$ Research Fellow, School of Property, Construction and Project Management, RMIT University, GPO Box 2476, Melbourne, Victoria 3001, Australia

${ }^{3}$ Associate Professor, School of Property, Construction and Project Management, RMIT University, GPO Box 2476, Melbourne, Victoria 3001, Australia
} 


\section{Introduction}

\section{Safety management in construction}

Considerable research has been undertaken in the construction management domain to identify the determinants of project safety performance. Contemporary models of incident causation in the construction industry recognize that incidents are caused by a complex interaction between proximal factors, including site conditions and workers behaviour, and distal factors, including the safety responses of clients, designers, managers and supervisors engaged in the oversight of construction work (Suraji et al. 2001). Thus, some researchers have focused upon the influence of owners/clients of the construction industry (Huang \& Hinze, 2006), as well as the designers of buildings and structures (Gambatese, et al. 2005). Construction management researchers have also examined the influence of variables at the level of the construction firm and/or project on occupational safety performance. Overwhelmingly, objective safety performance has been linked to the quality of safety management activity in construction organizations or projects (Fang et al. 2004, Mohammed, 1999). Research demonstrates that managers at different levels, including senior managers and first-level supervisors, have a significant impact upon safety performance in the construction industry (Sawacha et al. 1999; Choudhry \& Fang, 2008). MacDonald et al. (2009) report a 'top down' cascading management influence on safety performance at a large university construction project in the USA, in which commitment to safety was driven by the client and transmitted through the managerial hierarchy to create a shared understanding of the importance of safety at all levels in the project. Recognition of the impact of management action (or inaction) on safety performance in the construction industry has led to an increased 
interest in psychological and social determinants of safety performance, in particular how people perceive and respond to their work environment (Torner \& Poussette, 2009). Construction workers' are believed to develop shared perceptions of the safety response of referent others, including senior managers, supervisors and co-workers (Melia et al. 2008). Safety climate theory suggests that these perceptions are then socially transmitted to become collective values, norms and behaviours within workgroups, projects and organizations which, in turn, influence safety performance. Empirical evidence in the construction management literature supports this proposition. For example, in a large quantitative analysis utilizing structural equation modelling, Molenaar et al. (2009) identified perceptions of managers' response to safety as the most influential determinant of safety performance in construction projects.

\section{Safety climate}

Neal and Griffin (2006: pp 946-947) define safety climate as 'individual perceptions of the policies, procedures and practices relating to safety in the workplace.' Safety climate is believed to shape workers' behavior through the expectations they form about how organizations value and reward safety (Zohar \& Luria, 2005). A great deal of interest has been given to the extent to which safety climate predicts safety performance within organizations (Cooper \& Phillips 2004). There is considerable evidence that strong and positive safety climates are linked to higher levels of safety performance. For example, Tharaldsen et al. (2008) report a significant inverse correlation between safety climate perceptions and accident rates in the offshore industry, while Mearns et al. (2003) showed that offshore installations returning a lower proportion of self-reported accidents

were characterized by more favorable safety climates. Varonen and Mattila (2000) report 
safety climate to be inversely correlated with the accident rate in wood processing companies and, in the Australian health sector, Neal and Griffin (2006) report that safety climate measured at one point in time positively predicted subsequent safety motivation and self-reported safety-related behavior. Clarke (2006) conducted a comprehensive meta-analysis of safety climate research and reports a consistent positive link between safety climate and safety performance in prospective studies (i.e. those in which safety performance was monitored after the measurement of safety climate was undertaken). Safety climate has also been linked to an organization's ability to appropriately attribute incident causes and learn lessons from safety incidents (Hofmann and Stetzer, 1998).

\section{Safety climate in construction}

Safety climate has been examined in the construction industry (Dedobbeleer \& Beland, 1991). Consistent with research in other industries, there is empirical evidence to support a positive link between safety climate and the safety performance of construction organizations (Gillen et al., 2002). In Hong Kong, Siu et al.(2004) measured how construction workers perceived the safety responses of themselves, their colleagues, management, company safety officers and their supervisors, reporting that aggregated safety climate scores were directly related to self-reported injury rate. Zhou et al. (2008) report that two climate dimensions (management commitment and workmates' influence) exert significantly greater influence on self-reported safety behavior than workers’ personal experiences of training and safety in the Hong Kong construction context. In a lagged, two-wave study of Swedish construction workers, Poussette et al. (2008) report 
that safety climate scores at one point in time significantly predicted self-reported safety behaviors seven months later (after controlling for safety behavior at time one).

\section{Group-level safety climates}

The majority of safety climate studies have focused on the organization as the unit of analysis. However, Zohar (2000) proposed two levels of safety climate: (i) that arising from the formal organization-wide policies and procedures established by top management; and (ii) that arising from the safety practices associated with the implementation of company policies and procedures within workgroups. Zohar tested this proposition in a manufacturing context and confirmed that workgroup members develop a shared set of perceptions of supervisory safety practices, and discriminate between perceptions of the organization's safety climate and the workgroup safety climate. Zohar suggests that the prevailing group safety climate relates to patterns of supervisory safety practices, or ways in which organization level policies are implemented within each workgroup or sub-unit. In support of this, Johnson (2007) revealed that perceptions of supervisors' safety actions predicted safety behavior and the occurrence of incidents in the manufacturing sector.

Arguably, the group safety climate should be a stronger predictor of safety performance than organization level safety climate, especially in large organizations, because most workers have little contact with top management and are more likely to be influenced on a day-to-day basis by interactions with members of their immediate workgroup, including the supervisor and coworkers. The strength of group-level influences on safety was 
highlighted by a study of macro- (organizational) and micro- (group level) factors on workers’ safety performance conducted by Simard and Marchand (1994). In this research, supervisory practices were reported to be the strongest predictor of workgroups' propensity to take safety initiatives (Simard \& Marchand 1995) and to comply with safety rules (Simard \& Marchand 1997). The effect of workgroup and supervisory practices were considerably higher than macro- (organizational) factors, such as top management commitment to safety espoused by organizational safety policies. Further, Simard and Marchand (1995) found that these macro- (organization-level) factors influenced workers' safety behavior indirectly via group-level safety factors. This finding is consistent with the assertion of Christian et al. (2009) that proximal antecedents of safety performance will have a stronger influence than distal antecedents.

\section{The importance of first level supervisors}

First level ssupervisors' responses to safety are a key determinant in the creation of subordinates' beliefs about the importance of safety to the organization (Zohar 2002). Maierhofer et al. (2000) demonstrate two ways in which supervisors influence subordinates' safety behavior. First, they suggest that supervisors' safety values are internalized and adopted by their subordinates. Supervisors act as powerful role models exercising substantial influence upon their subordinates. When managers clearly and explicitly annunciate their strong safety values and reinforce these values with consistent behavior, Maierhofer et al. suggest that workers take on similar values. Second, Maierhofer and her colleagues found a strong relationship between supervisors' safety behavior and that of subordinates. Appropriate behavior is modeled by supervisors and 
adopted by workgroup members. The implication of these findings is that desired safety values and behaviors should be enacted across different hierarchical levels of an organization and first level supervisors play a key role in translating top management commitment to safety into safety values and practices within workgroups.

\section{Aim}

The present research aimed to quantitatively evaluate the role played by first level supervisors in shaping the safety performance of workgroups in the Australian construction supply chain. Specific research objectives were:

- to measure multiple levels of safety climate in a sample of Australian construction workers;

- to explore the relationship between safety climate perceptions and injury frequency rates; and

- to examine whether the relationship between perceptions of the organizational safety climate and injury frequency rate is mediated by the group-level safety climate.

Mediator variables explain how or why a predictor variable influences an outcome variable (Baron \& Kenny, 1986). Thus, group-level safety climate is viewed as a mechanism through which the organizational safety climate influences injury frequency rates. Figure 1 depicts the hypothesis that group safety climate mediates the relationship between the organizational safety climate and injury frequency rates. 
The question of whether the relationship between organization-level safety climate and workgroup safety performance is mediated by group level safety climate perceptions is important for both safety management theory and practice. On a theoretical level, testing the mediation hypothesis provides more precise understanding of the mechanism of managerial influence within organizations. Latane' (1981) argues that social impact, defined as behaviour change arising "as a result of the real, implied, imagined presence or actions of other individuals” (p. 343), is a function of the strength (importance), intimacy (proximity), and number of people exerting the influence. The greater the importance, proximity and number of referents, the more likely an individual will change their behaviour as a result of their social context.

Safety climate is a component of the social context within organizations. Although previous research in the construction industry has linked both perceptions of top managers’ safety response (an organization-level safety climate variable) and perceptions of supervisors' safety response (a group-level safety climate variable) with safety performance, researchers have not yet tested whether organizational and group level safety climates have an independent (i.e., additive) effect on safety performance or whether the relationship between organizational safety climate and safety performance is mediated by local workgroup safety climates. Consistent with Latané, support for the mediation hypothesis would be consistent with the social impact theory.

On a practical level, evidence of a mediation effect would also have implications for the design of safety management interventions within organizations because it would suggest 
that the demonstration of safety commitment by senior managers will not, by itself, have a substantial impact upon workgroup safety performance. Full or partial mediation would suggest that first level supervisors must also respond positively to safety in order to achieve good safety outcomes within workgroups.

Figure 1: Proposition that group safety climate mediates the relationship between the organizational safety climate and injury frequency rate

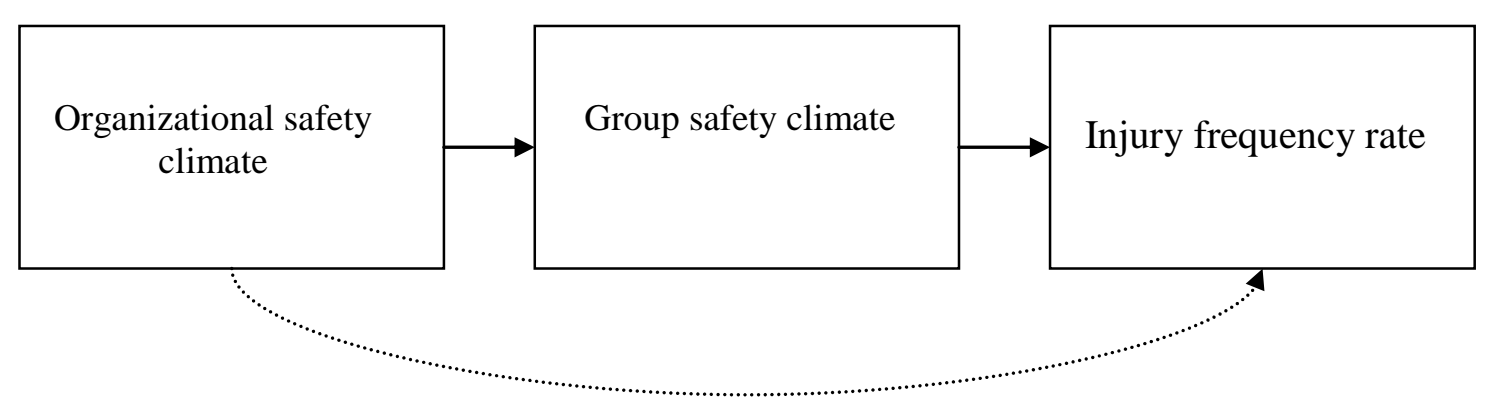

Note: Unbroken line denotes full mediation pathway

Dashed line denotes partial mediation pathway

\section{Research methods}

\section{Data collection}

The survey was designed to measure three aspects of safety climate: (i) perceptions of the organizational safety response; (ii) perceptions of supervisors’ safety response and (iii) perceptions of coworkers' safety response. This is consistent with Melia et al. (2008) who suggest that safety climate should be analysed from the point of view of the agent 
that performs or is responsible for specific safety activities within organizations. Melia et al. (2008) define safety climate dimensions according to the "agent” of the safety climate’s actions or omissions. Thus, Melia et al. (2008) suggest a multi-level safety climate model in which safety climate variables include the organizational safety response (OSR), the supervisors’ safety response (SSR) and the co-workers’ safety response (CSR). One of the benefits of this approach to measuring safety climate is that it enables a separate diagnosis of each agent's safety response and permits researchers to assess the relationships between them

Items used to measure perceptions of the organization's safety response were taken from the HSE’s Safety Climate Tool (2002). Consistent with Zohar and Luria (2005), the survey measured perceptions of management commitment to safety as the core meaning of safety climate. While there is limited agreement among researchers concerning first order safety climate factors, e.g., worker involvement, the status of safety personnel or safety training, there is widespread agreement that management commitment constitutes a global higher order safety climate factor. Consequently, the first part of the survey, which measured perceptions of the organizational safety response, included the following items "I feel that at [company name] management are concerned about my health and safety” and “[Company name’s] management only bother to look at health and safety after there has been an accident” (reversed score). All organizational safety response items were rated on a five point Likert scale ranging from 'strongly disagree' (1) to ‘strongly agree’ (5). 
The second part of the survey utilized a ten-item group safety climate scale developed by Zohar (2000). The scale measures supervisors' safety response. Example items are "Whenever pressure builds up, my supervisor wants us to work faster, rather than by the safe work procedures" (reverse scored), and "My immediate supervisor often talks to me about health and safety.” All supervisors' safety response items were rated on a five point Likert scale ranging from ‘strongly disagree' (1) to ‘strongly agree’ (5).

Finally, coworkers' safety response was measured using five items adopted from Burt et al.'s considerate and responsible employee (CARE) scale (Burt et al. 1998). Example items are "Coworkers should be warned when their actions are unsafe," and "Workers should assist each other with tasks to ensure safety.” The remaining ten questions, which also measured coworkers' safety response, were adopted from the UK Health and Safety Executive Safety Climate Survey (HSE 2002). Example items are "My workmates encourage others to be safe" and "Some of my team pay little attention to health and safety" (reverse scored). All items were rated by respondents using a five point Likert scale ranging from 5 (strongly agree) to 1 (strongly disagree).

The dependent variable, i.e., injury frequency rate, was a combination of the workgroup lost time and medical treatment injury frequency rates for the twelve months prior to conducting the survey in each organization. This data was obtained from company records. Each individual respondent was assigned the injury frequency rate score for the workgroup in which they were situated. 
Data were collected within three organizations operating in the Australian construction supply chain. These organizations were selected on the basis of their willingness to participate in the research. The non-random selection of organizations constitutes a threat to the external validity of the results and, consequently, no are made attempts to generalize the findings to the industry. Prior to the commencement of data collection, workers were advised that participation was voluntary and that their responses would be anonymous. No inducements were given to participants.

Study one was undertaken within the regional construction and maintenance works district of a state-based road construction and maintenance organization in the Southeast of Australia. Four work centres make up the works district. Each work centre consists of a number of work crews. Paper-based questionnaires were administered during work hours. A member of the research team visited worksites within the region to distribute and collect the surveys. Workers not available during the survey administration were invited to complete the questionnaire at a later date. Completed surveys were placed in self-sealed envelopes and returned directly to the research team, via the Regional Site Safety Coordinator.

Study two was undertaken at a hospital construction project in Melbourne, Victoria. Surveys were administered using the 'TurningPoint' automated response system with 'KeyPad' hand-held devices. The use of this system helps to overcome issues of literacy as survey questions are projected onto a screen and read out by the researcher. The response system can be set so that if a respondent presses an 'out of range' value (for 
example six), the response is not accepted. The researcher can monitor responses to determine completeness of data as it is being collected. The advantages of this system include the completeness of data and minimisation of human error in data entry (See de Quiros et al., 2008 for an analysis of the impact of human error in data entry). Participants were invited, by the principal contractor’s Site Safety Coordinator to participate in the survey during normal work hours. Surveys were completed in the site office.

Study three was undertaken at the Melbourne operations of a national steel reinforcement manufacturing organization. Data were collected from sixteen workgroups across four sites in metropolitan Melbourne. As in study two, surveys were administered using the 'TurningPoint' automated response system with ‘KeyPad' hand-held devices. Workers unable to complete the initial survey were invited to complete a paper-based version of the questionnaire at a later date. Completed surveys were placed in self-sealed envelopes and returned directly to the research team, via the National Manager - Partnering.

\section{Data analysis}

Data were analysed using a principal components analysis with varimax rotation to determine the factor structure of the safety climate items. Internal consistency reliability of the safety climate components was then assessed using Cronbach's alpha. Bi-variate (Pearson) correlations were then performed to explore the relationships between the resulting safety climate factors and the injury frequency rate. In order to test whether group safety climate mediated the relationship between organizational safety climate and 
injury frequency rate, procedures described by Baron and Kenny (1986) were followed. Baron and Kenny suggest that to test for mediation, three regression equations must be estimated as follows:

- the mediator (group safety climate) is regressed on the independent variable (organizational safety climate);

- the dependent variable (injury frequency rate) is regressed on the independent variable (organizational safety climate); and

- the dependent variable (injury frequency rate) is regressed on both the independent variable (organizational safety climate) and the mediator (group safety climate).

To establish mediation, the independent variable must affect the mediator in the first equation; the independent variable must affect the dependent variable in the second equation; and the mediator must affect the dependent variable in the third equation. If these conditions hold, then the effect of the independent variable on the dependent variable in the third equation must be less in the third equation than in the second.

\section{Results}

The sample

A total of 400 surveys were received from the three organizations. One hundred and one (25.2\%) respondents worked for the road construction and maintenance organization, 163 respondents (40.8\%) worked at the steel reinforcement manufacturing organization and 136 (34.0\%) worked at the hospital construction project. 


\section{Principal components analysis}

The initial unforced PCA of the organizational safety response items revealed the presence of three components with eigenvalues exceeding one. However, an inspection of the scree plot revealed a clear break after the second component. A two component was further supported by the results of parallel analysis, which suggested only two components. Thus a forced two component solution was examined. The two component solution explained $33.55 \%$ and $10.82 \%$ of variance respectively and there was no double loading of items onto components. An examination of the wording of items revealed a conceptual distinction between perceptions of management commitment to safety (e.g., '[Company name] really cares about the health and safety of the people who work here') and perceptions of whether safety is treated as a priority relative to other organizational goals (e.g. 'I am not given enough time to get the job done '). Thus, the components were labeled 'Top management commitment to safety' and 'Organizational priority placed on safety' and treated as separate variables in further analysis. Cronbach's alpha coefficients for these components were 0.872 and 0.813 respectively.

An initial unforced PCA of supervisors' safety response items scale produced two components with eigenvalues of 4.49 for component one and 1.23 for component two, explaining $40.87 \%$ and $11.28 \%$ of the variance respectively. The two component structure was supported by a parallel analysis. An examination of the items indicated that their loadings were consistent with Zohar's original conceptualization of group safety climate (Zohar 2000). Thus, following Zohar (2000) the two components were labelled 
‘Supervisors’ Safety Actions’ and 'Supervisors’ Safety Expectations’ respectively. The former reflects workers’ perceptions of supervisory reactions to subordinates' safety conduct (i.e. in giving positive or negative feedback) and the latter reflects workers’ perceptions of their supervisors' safety-related expectations. The internal consistency reliability of the two Cronbach's alpha coefficients for Supervisors' Safety Actions and Supervisors' Safety Expectations were 0.80 and 0.71 respectively, indicating acceptable internal consistency reliability.

An initial unforced PCA of the coworkers' safety response items produced three components with eigenvalues exceeding one. However, an inspection of the scree plot revealed a clear break after the second component and a two component structure was also suggested by the results of parallel analysis. Thus, a forced two component solution was examined. The first component explained 30.6\% and the second component explained $18.5 \%$ of variance respectively. The items loading on the first component were those adopted from the HSE safety climate tool, while items loading on the second component were those adopted from Burt et al. (2008). An examination of the wording of items revealed a conceptual distinction between perceptions of coworkers' actual safety response (e.g., 'People here always work safely even when they are not being supervised') and perceptions of how coworkers should ideally respond in relation to safety (e.g. 'Workers should assist each other with tasks to ensure safety '). Thus, the components were labelled ‘Coworkers’ Actual Safety Response’ and ‘Coworkers’ Ideal Safety Response' and treated as separate variables in further analysis. Cronbach's alpha coefficients for ‘Coworkers’ Actual Safety Response’ and ‘Coworkers’ Ideal Safety 
Response' were 0.85 and 0.80 respectively, indicating acceptably high internal consistency reliability. ${ }^{4}$

\section{Bivariate correlations}

Table 1 shows the bivariate correlations between each of the safety climate dimensions included in the analysis and the injury frequency rate of the workgroups from which respondents were drawn. As expected, there was a significant positive correlation between organizational and group-level safety climate. Perceptions of top management commitment to safety were strongly positively correlated with perceptions of supervisors' safety actions ( $\mathrm{r}=.604, \mathrm{p}=.000)$, supervisors' safety expectations $(\mathrm{r}=.492, \mathrm{p}=.000)$, coworkers actual safety response $(\mathrm{r}=.539, \mathrm{p}=.000)$ and coworkers' ideal safety response, $(\mathrm{r}=.207, \mathrm{p}=.000)$. There was a significant inverse correlation between perceptions of top management's commitment to safety and the combined lost time/medical treatment injury rate $(\mathrm{r}=-.138, \mathrm{p}=.043)$. Perceptions of supervisors' safety expectations were also inversely correlated with the lost time/medical treatment injury rate $(\mathrm{r}=-.272, \mathrm{p}=.000)$.

\footnotetext{
${ }^{4}$ A complete list of safety climate survey items and PCA results is available from the first author on request.
} 
Table 1: Bivariate correlations between safety climate dimensions and injury frequency rate

\begin{tabular}{|c|c|c|c|c|c|c|c|}
\hline & 1 & 2 & 3 & 4 & 5 & 6 & 7 \\
\hline $\begin{array}{l}\text { 1. Top management } \\
\text { commitment to safety }\end{array}$ & .872 & & & & & & \\
\hline $\begin{array}{l}\text { 2. Organizational priority } \\
\text { placed on safety }\end{array}$ & $.526^{* *}$ & .813 & & & & & \\
\hline 3. Supervisors' safety actions & $.604^{* *}$ & $.367^{* *}$ & .809 & & & & \\
\hline $\begin{array}{l}\text { 4. Supervisors' safety } \\
\text { expectations }\end{array}$ & $.492^{* *}$ & $.568^{* *}$ & $.539^{* *}$ & .714 & & & \\
\hline $\begin{array}{l}\text { 5. Coworkers' actual safety } \\
\text { response }\end{array}$ & $.539^{* *}$ & $.360^{* *}$ & $.535^{* *}$ & $.373^{* *}$ & .846 & & \\
\hline $\begin{array}{l}\text { 6. Coworkers' ideal safety } \\
\text { response }\end{array}$ & $.207^{* *}$ & .072 & .101 & .032 & $.169^{* *}$ & .793 & \\
\hline $\begin{array}{l}\text { 7. Lost time/medical } \\
\text { treatment injury rate }\end{array}$ & $-.138^{*}$ & -.056 & -.115 & $-.272^{* *}$ & .007 & .006 & $\mathrm{~N} / \mathrm{A}$ \\
\hline
\end{tabular}

** Correlation is significant at the 0.01 level (2-tailed).

* Correlation is significant at the 0.05 level (2-tailed).

Cronbach's alpha coefficients shown on the diagonal

Regression analysis

Prior to performing the regression analysis, relevant variables were screened to ensure that the assumptions normal distribution and equality of variance were not violated. The procedures described by Baron and Kenny (1986) were then followed to determine the extent to which the relationship between top management commitment to safety and workgroup injury frequency rate was mediated by perceptions of supervisors' safety expectations. 
Table 2 shows the results of the tests for mediation. In the first equation, perceptions of top management commitment to safety predicted perceptions of supervisors' safety expectations in equation $1(\beta=.49, \mathrm{p}=.000)$. In the second equation perceptions of top management commitment to safety predicted injury frequency rate $(\beta=-.14, \mathrm{p}=.043)$. In the third equation, perceptions of supervisors' safety response predicted injury frequency rate $(\beta=-.51, \mathrm{p}=.000)$ and the effect of perceptions of top management commitment to safety on injury frequency rate is lower in the third equation $(\beta=.044, \mathrm{p}=.494)$ than it was in the second. Thus, the conditions required to establish mediation were met. Further, the relationship between perceptions of top management commitment to safety and injury frequency rate was non-significant in the third equation, indicating that the 'effect' of perceptions of top management commitment to safety on injury frequency rate is fully mediated by perceptions of supervisors' safety expectations 
Table 2: Regression analysis examining supervisors' safety expectations as a mediator of the relationship between top management commitment to safety and injury frequency rate

\begin{tabular}{|c|c|c|c|c|c|c|}
\hline Step & Variable & B & SE & $\beta$ & $\mathrm{t}$ & $p$ \\
\hline \multirow{2}{*}{$\begin{array}{l}\text { Equation 1: Supervisors' safety expectations } \\
\text { regressed on top management commitment to } \\
\text { safety }\end{array}$} & Constant & .85 & .24 & & 3.57 & .000 \\
\hline & $\begin{array}{l}\text { Top management } \\
\text { commitment to } \\
\text { safety }\end{array}$ & .72 & .06 & .49 & 11.29 & .000 \\
\hline \multirow{2}{*}{$\begin{array}{l}\text { Equation 2: Injury frequency rate regressed on } \\
\text { top management commitment to safety }\end{array}$} & Constant & 418.51 & 104.54 & & 4.003 & .000 \\
\hline & $\begin{array}{l}\text { Top management } \\
\text { commitment to } \\
\text { safety }\end{array}$ & -59.35 & 29.10 & -.14 & -2.04 & .043 \\
\hline \multirow{3}{*}{$\begin{array}{l}\text { Equation 3: Injury frequency rate regressed on } \\
\text { top management commitment to safety and } \\
\text { supervisors' safety expectations }\end{array}$} & Constant & 1262.11 & 141.25 & & 8.94 & .000 \\
\hline & $\begin{array}{l}\text { Top management } \\
\text { commitment to } \\
\text { safety }\end{array}$ & 18.86 & 27.51 & .044 & .69 & .494 \\
\hline & $\begin{array}{l}\text { Supervisors' safety } \\
\text { expectations }\end{array}$ & -338.22 & 42.90 & -.51 & -7.88 & .000 \\
\hline
\end{tabular}

\section{Discussion}

\section{Cascading management influence}

The results suggest that top managers have a significant influence on safety within organizations in the construction supply chain, but that this influence is indirect rather than direct. Perceptions of top managers’ commitment to safety were strongly and positively correlated with perceptions of supervisors’ safety actions and expectations as 
well as with perceptions of coworkers' ideal and actual safety. This suggests a cascading influence by which management commitment to safety filters down through organizational hierarchies. This finding is consistent with that of Melia et al. (2008) who report that perceptions of the organizational safety response and supervisor safety response were strongly correlated in two construction samples.

The results confirm the importance of the role of first-level supervisors in influencing group-level safety climates and the safety performance of the groups that they supervise. The pathway by which management commitment to safety influences workgroup injury performance is through the development of shared perceptions of the safety expectations of their immediate supervisors within workgroups. Supervisors act as a "conduit” through which organizational safety priorities are communicated and provide important feedback to front-line workers concerning the appropriateness of their behavior (Niskanen 1994). The fact that the relationship between top management commitment to safety and workgroup injury frequency rates was fully mediated by perceptions of supervisors' safety expectations highlights the critical role played by supervisors in the safety management process. Without supervisors communicating high safety expectations, the influence of senior managers appears to be insignificant. This finding also demonstrates the importance of adopting a multi-level approach to the measurement and analysis of safety climate within construction organizations.

The influence of supervisors on safety performance is likely to be increased in the construction context because construction work is highly decentralized, with productive 
work undertaken at sites remote from the corporate office. This geographical dispersion is likely to increase the behavioral influence of supervisors relative to senior management. Construction work is also largely non-routine, necessitating the exercise of supervisory discretion in the interpretation of formal safety policies and procedures. In this context, the role of supervisors in shaping subordinates' safety behavior is likely to be considerably greater than in stable work contexts characterized by routine production processes.

In order to develop safety-supportive climates within workgroups, it is critical that supervisors are consistent in the way that they emphasise safety in their interactions with employees. Climates are formed on the basis of the day-to-day interactions and observations of supervisors' behavior. Over time, supervisors' behavior is observed to form a pattern. Positive and strong safety climates will develop only to the extent that supervisors are consistent in what they say and do in relation to safety. Thus, similar events or situations should elicit similar safety responses from supervisors reflecting stability in the importance placed upon safety. Where the supervisors' safety response is perceived by employees to be contingent upon the circumstances, for example if a supervisor changes his/her behavior when facing production pressure, the resulting group safety climate will be weak (Zohar \& Luria 2004).

\section{Implications of the research}

The findings have important implications for research as they highlight the need to evaluate multi-level models of safety climate in the construction industry. In particular, 
there is a need to better understand the mechanisms by which management commitment to safety 'cascades' down to lower tiers of management to ensure that supervisors' safety responses remain consistent with organizational safety commitments.

The findings also highlight the potential benefit of cross-level supervisory safety leadership interventions. For example, testing whether interventions designed to develop safety leadership behavior in supervisors can improve the safety performance of construction workgroups (Zohar \& Luria, 2003).

The research has important practical implications for the management of safety within organizations. They highlight the importance of first level supervisors in translating organizational safety policies and procedures into workgroup safety practices. As many first-level supervisors in the Australian construction industry, e.g. foremen and leading hands, have a trade background, most have not undertaken formal management education. Thus, there is potential to provide formal training to specifically develop leadership capability in first-level supervisors in relation to safety. The results suggest that this could yield significant dividends for construction organizations in terms of reduced lost time and medical treatment injuries.

\section{Conclusions}

The results reveal the import role played by first level supervisors as the linking mechanism between the organizational safety climate, specifically perceptions of top 
management commitment to safety, and injury rates within construction organizations. The role played by group-level safety climate in mediating the relationship between organizational safety climate and safety performance highlights the importance of adopting a multi-level approach to the analysis of safety climate within construction organizations.

\section{Limitations and future research}

No attempt is made to generalize the results of the survey to the Australian construction industry. Participating companies were selected using a convenience sampling approach, constituting a significant threat to the external validity of the research. The research was also limited by the reliance upon reportable lost time and medical treatment injury rates as the measure of workgroup safety performance. The relative infrequency of these events could explain the failure to find a consistent and significant relationship between several of the safety climate dimensions and workgroup safety performance. Future research, using prospective designs and more sensitive measures of safety performance are recommended.

\section{Acknowledgement}

This research was funded by the Australian Research Council under Linkage Project Grant LP0668012. Grateful thanks are also extended to employees of the Roads and Traffic Authority (NSW), Baulderstone Pty Ltd and the Australian Reinforcement Company. In particular, the authors acknowledge the assistance of Tony Page, Lance Breen and Paul McDonald in facilitating the data collection. 


\section{References}

Baron, R. M. and Kenny, D. A., (1986), The moderator-mediator variable distinction in social psychological research: Conceptual, strategic and statistical considerations, Journal of Personality and Social Psychology, 51, 1173-1182.

Burt C. D. B., Sepie, B. \& McFadden, G., (2008), The development of a considerate and responsible safety attitude in work teams, Safety Science, 46, 79-91.

Burt, D. B., Chmiel, N. \& Hayes, P., (2009), Implications of turnover and trust for safety attitudes and behavior in work teams, Safety Science, 47, 1002-1005.

Choudhry, R. M. \& Fang, D., (2008), Why operatives engage in unsafe work behavior: Investigating factors on construction sites, Safety Science, 46, 566-584

Christian, M., Bradley, J., Wallace, C., \& Burke, M., (2009), Workplace Safety: A Meta-Analysis of the Roles of Person and Situation Factors, Journal of Applied Psychology, 94, 1103-1127

Clarke, S., (2006), The relationship between safety climate and safety performance: A meta-analytic review, Journal of Occupational Health Psychology, 11, 315-327.

Cooper, M. D. and Phillips, R. A., (2004), Exploratory analysis of the safety climate and safety behavior relationship, Journal of Safety Research, 35, 497-512.

Dedobbeleer, N. and Béland, F. (1991), A safety climate measure for construction sites, Journal of Safety Research, 22, 97-103.

de Quiros, A C B, Lopez, R, Aranda-Mena, G and Edwards, P (2008) Human reliability as a source of error in research. In: Dainty, A (Ed) Procs 24th Annual ARCOM Conference, 1-3 September 2008, Cardiff, UK, Association of Researchers in Construction Management, 687-696.

Fang, D. P., Huang, X. Y. \& Hinze, J., (2004), Benchmarking Studies on Construction Safety Management in China, Journal of Construction Engineering and Management, 130, 424-432 
Gambatese, J. A., Behm, M. \& Hinze, J. W., (2005), Viability of designing for construction worker safety, Journal of Construction Engineering and Management, 131, 1029-1036.

Gillen, M., Baltz, D., Gassel, M., Kirsch, L. and Vaccaro, D., (2002), Perceived safety climate, job demands and coworker support among union and nonunion injured construction workers, Journal of Safety Research, 33-51.

Health and Safety Executive (HSE), (2002), Evaluating the Effectiveness of the Health and Safety Executives Health and Safety Climate Survey Tool, HMSO, London.

Hofman, D. A. \& Stetzer, A., (1998), The role of safety climate and communication in accident interpretation: Implications for learning from negative events, Academy of Management Journal, 411, 644657.

Huang, X. \& Hinze, J., (2006a), Owner’s role in construction safety, Journal of Construction Engineering and Management, 132, 164-173.

Johnson, S. E., (2007), The predictive validity of safety climate, Journal of Safety Research, 38, 511-521. Latane', B. (1981). The psychology of social impact. American Psychologist, 36, 343-356.

Lingard, H., Cooke, T. \& Blismas, (2009), Group-level safety climate in the Australian construction industry: Within-group homogeneity and between-group differences in road construction and maintenance. Construction Management and Economics, 27, 419-432.

Maierhofer, N. I., Griffin, M.A. \& Sheehan, M., (2000), Linking manager values and behavior with employee values and behavior: a study of values and safety in the hairdressing industry, Journal of Occupational Health Psychology, 5, 417-427.

Mearns, K., Whitaker, S. M. \& Flin, R., (2003), Safety climate, safety management practice and safety performance in offshore environments, Safety Science, 41, 641-680 McDonald, M., Lipscomb, H. J., Bondy, J., \& Glazner, J., (2009), “Safety is everyone's job:” The key to safety on a large university construction site, Journal of Safety Research , 40, 53-61

Melia, J. L., Mearns, K., Silva, S. A., and Lima, M. L., (2008), Safety climate responses and the perceived risk of accidents in the construction industry, Safety Science, 46, 949-958. 
Mohamed, S. (1999), Empirical investigation of construction safety management activities and performance in Australia, Safety Science, 33, 129-142.

Molenaar, K. R., Park, J. I. \& Washington, S., (2009), Framework for Measuring Corporate Safety Culture and Its Impact on Construction Safety Performance, Journal of Construction Engineering and Management, 135, 488-496

Neal, A. and Griffin, M. A., (2006), A study of the lagged relationships among safety climate, safety motivation, safety behavior and accidents at individual and group levels, Journal of Applied Psychology, 91, 946-953.

Niskanen, T., (1994), Assessing the safety environment in work organization of road maintenance jobs, Accident Analysis and Prevention, 26, 27-39.

Pousette, A., Larsson, S. and Törner, M. (2008), Safety climate cross-validation, strength and prediction of safety behavior, Safety Science, 46, 398-404.

Tharaldsen, J. E., Olsen, E. and Rundmo, T. (2008), A longitudinal study of safety climate on the Norwegian continental shelf, Safety Science, 46, 427-439

Sawacha, E., Naoum, S. \& Fong, D. (1999), Factors affecting safety performance on construction sites, International Journal of Project Management, 17, 309-315

Simard, M. \& Marchand, A., (1994), The behavior of first-line supervisors in accident prevention and effectiveness on occupational safety, Safety Science, 17, 169-185.

Simard, M. \& Marchand, A., (1995), A multi-level analysis of organizational factors related to the taking of safety initiatives by work groups, Safety Science, 21, 113-129.

Simard, M. \& Marchand, A., (1997), Workgroups’ propensity to comply with safety rules: the influence of micro-macro organizational factors, Ergonomics, 40, 172-188.

Siu, O., Phillips, D. R. \& Leung, T., (2004), Safety climate and safety performance among construction workers in Hong Kong: The role of psychological strains as mediators, Accident Analysis and Prevention, 36, 359-366 
Suraji, A., Duff, A. R., \& Peckitt, S. J. (2001), Development of causal model of construction accident causation, Journal of Construction Engineering and Management, 127, 337-344.

Törner, M. \& Pousette, A., (2009), Safety in construction - a comprehensive description of the characteristics of high safety standards in construction work, from the combined perspective of supervisors and experienced workers, Journal of Safety Research, 40, 399-409

Varonen, U. and Mattila, M., (2000), The safety climate and its relationship to safety practices, safety of the work environment and occupational accidents in eight wood-processing companies, Accident Analysis and Prevention, 32, 761-769.

Zhou, Q., Fang, D. P. \& Wang, X., (2008), A method to identify strategies for the improvement of human safety behavior by considering safety climate and personal experience, Safety Science, 46, 1406-1419.

Zohar, D., (2000), A group-level model of safety climate: Testing the effect of group climate on microaccidents in manufacturing jobs, Journal of Applied Psychology, 85, 587-596.

Zohar, D., (2002), The effects of leadership dimensions, safety climate and assigned priorities on minor injuries in work groups, Journal of Organizational Behavior, 23, 75-92.

Zohar, D. \& Luria, G., (2003), The use of supervisory practices as leverage to improve safety behavior: A cross-level intervention model, Journal of Safety Research, 34, 561-571.

Zohar, D. and Luria, G., (2004), Climate as a social-cognitive construction of supervisory safety practices: scripts as proxy of behavior pattern, Journal of Applied Psychology, 89, 322-333.

Zohar, D. \& Luria, G., (2005), A multilevel model of safety climate: Cross-level relationships between organization and group-level climates, Journal of Applied Psychology, 90, 616-628. 